\title{
Sequential Preparation of $\left[{ }^{18}\right.$ F]FLT and [18F]FMISO Employing Advion NanoTek ${ }^{\circledR}$ Microfluidic Synthesis System
}

\author{
Murthy R. Akula1 ${ }^{*}$, Thomas L. Collier², David W. Blevins' ${ }^{1}$, George W. Kabalka ${ }^{3}$, Dustin Osborne ${ }^{1}$ \\ ${ }^{1}$ The University of Tennessee Medicial Center, Knoxville, TN USA \\ ${ }^{2}$ Advion Bioscinces, Ithaca, NY, USA \\ ${ }^{3}$ The University of Tennessee, Knoxville, TN, USA \\ Email: *makula@utmck.edu
}

How to cite this paper: Akula, M.R., Collier, T.L., Blevins, D.W., Kabalka, G.W. and Osborne, D. (2019) Sequential Preparation of $\left[{ }^{18} \mathrm{~F}\right] \mathrm{FLT}$ and $\left[{ }^{18} \mathrm{~F}\right] \mathrm{FMISO}$ Employing Advion NanoTek ${ }^{\circledR}$ Microfluidic Synthesis System. Advances in Molecular Imaging, 9, 53-59.

https://doi.org/10.4236/ami.2019.94008

Received: March 21, 2019

Accepted: September 22, 2019

Published: September 25, 2019

Copyright () 2019 by author(s) and Scientific Research Publishing Inc. This work is licensed under the Creative Commons Attribution International License (CC BY 4.0).

http://creativecommons.org/licenses/by/4.0/

\begin{abstract}
One of the commercially available capillary-based microfluidic synthesizers is Advion NanoTek Microfluidic Synthesis System and is currently being used across the globe. The goal of this study is to demonstrate the system capability to perform the synthesis of two compounds sequentially without cleaning the equipment between the syntheses. We have chosen to prepare two key radiotracers [F-18]FLT and [F-18]FMISO. The basic microfluidic flow chemistry module was reconfigured to allow the hydrolysis of the second tracer in a vial using reactor 1 as a heat source and the system was integrated to semi-preparative high-performance liquid chromatography with a column selector and solvent selector. The decay corrected radio chemical yields of $\left[{ }^{18} \mathrm{~F}\right] \mathrm{FLT}$ and $\left[{ }^{18} \mathrm{~F}\right] \mathrm{FMISO}$ were found to be $28.5 \%$ and $38.6 \%$ respectively. The specific activity was determined to be $>2 \mathrm{Ci} / \mu \mathrm{mol}$.
\end{abstract}

\section{Keywords}

Sequential, Microfluidic, $\left[{ }^{18} \mathrm{~F}\right] \mathrm{FLT},\left[{ }^{18} \mathrm{~F}\right] \mathrm{FMISO}$

\section{Introduction}

The technical advantages of microfluidics include reduced reaction times, increased synthesis yields and decreased amounts of by-products due to the high surface to volume ratio. In addition, automated reaction optimization and reduced consumption of expensive precursors have been reported. The application of microfluidic technology has been pursued in the development of positron emission tomography tracer synthesizers during the past decade [1]-[8]. Since 
the first report of radiotracer synthesis using hydro-dynamically driven micro-reactor, various microfluidic devices have been described that include both capillary-based microfluidic synthesis platforms [9] [10] [11] and Lab-on-chip devices [12]. One of the commercially available capillary-based microfluidic synthesizers is Advion NanoTek ${ }^{\circledR}$ Microfluidic Synthesis System. In a typical set-up of this system, it has two reagent modules, a reactor module with four reactor slots and a concentrator module. The isotope is eluted from the ion-exchange cartridge and dried in the concentrator module. The reactants are stored in separate loops in the reagent modules and delivered to micro-channel reactors containing quartz capillary coils of varied lengths. These reactors are efficiently heated up to $220^{\circ} \mathrm{C}$ and the reagents are delivered using built-in syringe pumps. There are about 36 of these units being used across the globe and these tracers $\left[{ }^{18} \mathrm{~F}\right] \mathrm{FPEB}, \mathbf{1},[13],\left[{ }^{18} \mathrm{~F}\right] \mathrm{FMISO}, 2,[14]$ and $\left[{ }^{18} \mathrm{~F}\right] \mathrm{T}-807, \mathbf{3},[15]$ (Figure 1) have been synthesized as clinical doses for human studies under cGMP conditions. At most centers there is a demand for sequential preparation of two radiotracers. In order to ascertain the Advion NanoTek ${ }^{\circledR}$ Synthesis System capability of performing dual back-to-back syntheses without system cleaning in between the syntheses, we wish to report the preparation of two popular radiotracers $\left[{ }^{18} \mathrm{~F}\right] \mathrm{FLT}$ and $\left[{ }^{18} \mathrm{~F}\right] \mathrm{FMISO}$. This is the first ever reported sequential synthesis of two prominent tracers on a Microfluidic Synthesis Platform.

\section{Methods and Results}

$\left[{ }^{18} \mathrm{~F}\right] \mathrm{FLT}$, a thymidine analogue, is used to directly assess the tumor cell proliferation using PET and that does not accumulate in inflammatory processes as seen with $\left[{ }^{18} \mathrm{~F}\right] \mathrm{FDG}[15] .\left[{ }^{18} \mathrm{~F}\right] \mathrm{FLT}$ was synthesized (Figure 2) starting from 3- $\mathrm{N}$-Boc-5'-O-dimethoxytrityl-3'- $\mathrm{O}$-nosylthymidine, 4. Thus the nosylate precursor 4 was converted to $3-N$-Boc-5'-O-dimethoxytrityl- 3 '- $\left[{ }^{18} \mathrm{~F}\right]$ fluorothymidine, 5, by nucleophilic substitution of nosylate with $\left[{ }^{18} \mathrm{~F}^{-} \mathrm{F}^{-} / \mathrm{k}_{222} / \mathrm{K}_{2} \mathrm{CO}_{3}\right.$ complex [17]. The removal of protecting groups Boc and dimethoxytrityl was carried out by treating 5 with $2 \mathrm{NHCl}$ to obtain $\left[{ }^{18} \mathrm{~F}\right] \mathrm{FLT}$.
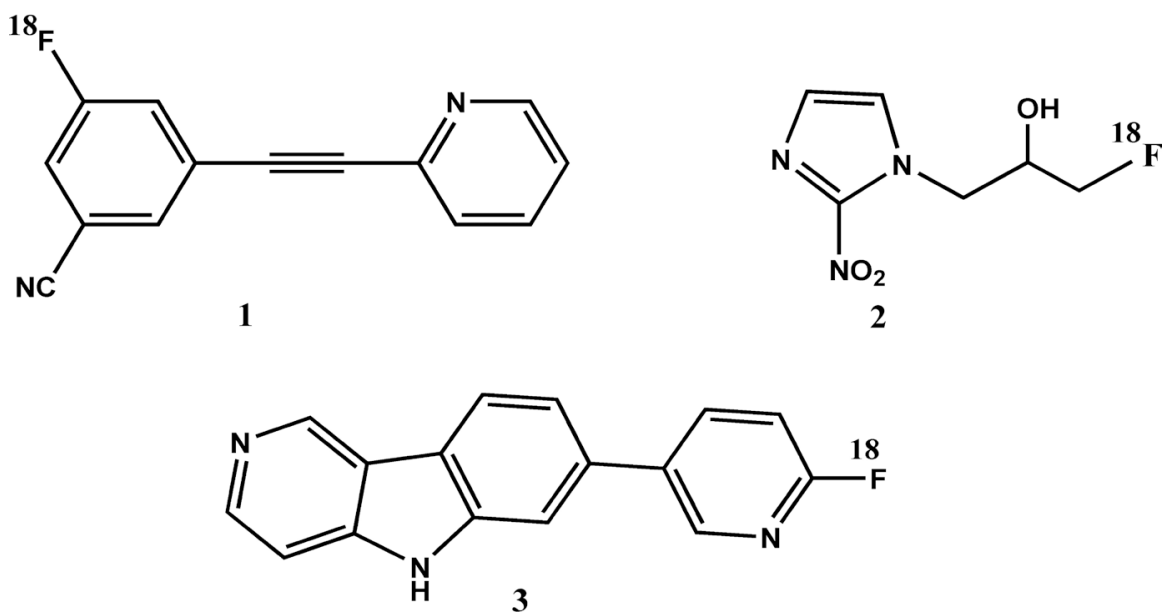

Figure 1. Tracers synthesized using Advion NanoTek platform for human use. 
$\left[{ }^{18} \mathrm{~F}\right] \mathrm{FMISO}$, a 2-nitroimidazole analogue, is used to quantitatively assess hypoxia in tumors for lung, brain and head and neck cancer patients [18] and in the hearts of patients with myocardial ischemia. $\left[{ }^{18} \mathrm{~F}\right] \mathrm{FMISO}$ was synthesized (Figure 3) from 3-(2'-nitro-1'-imidazolyl)-2-O-tetrahydropyranyl-1-O-p-toluenesulfonylpropane-1,2-diol, 7 in two steps. The tosylate group from the precursor 7 was nucleophilically displaced with $\left[{ }^{18} \mathrm{~F}\right] \mathrm{F}^{-}$to obtain THP protected $\left[{ }^{18} \mathrm{~F}\right] \mathrm{FMISO}, \mathbf{8}$. Deprotection of THP group was accomplished by hydrolysis using $1 \mathrm{NHCl}$ to obtain $\left[{ }^{18} \mathrm{~F}\right]$ FMISO.

Most radiosynthesis boxes can only prepare one tracer at a time and require full system cleaning prior to a second synthesis. Although radio syntheses are conducted in lead shielded fume hoods, cleaning of the equipment immediately after a first synthesis results in high radiation exposure to an operator. Advion NanoTek Microfluidic Synthesis System was used to successfully prepare both $\left[{ }^{18} \mathrm{~F}\right] \mathrm{FLT}$ and $\left[{ }^{18} \mathrm{~F}\right]$ FMISO in tandem. In order to achieve this goal, the NanoTek system was modified from the standard system as shown in Figure 4. Concentrator 1, not

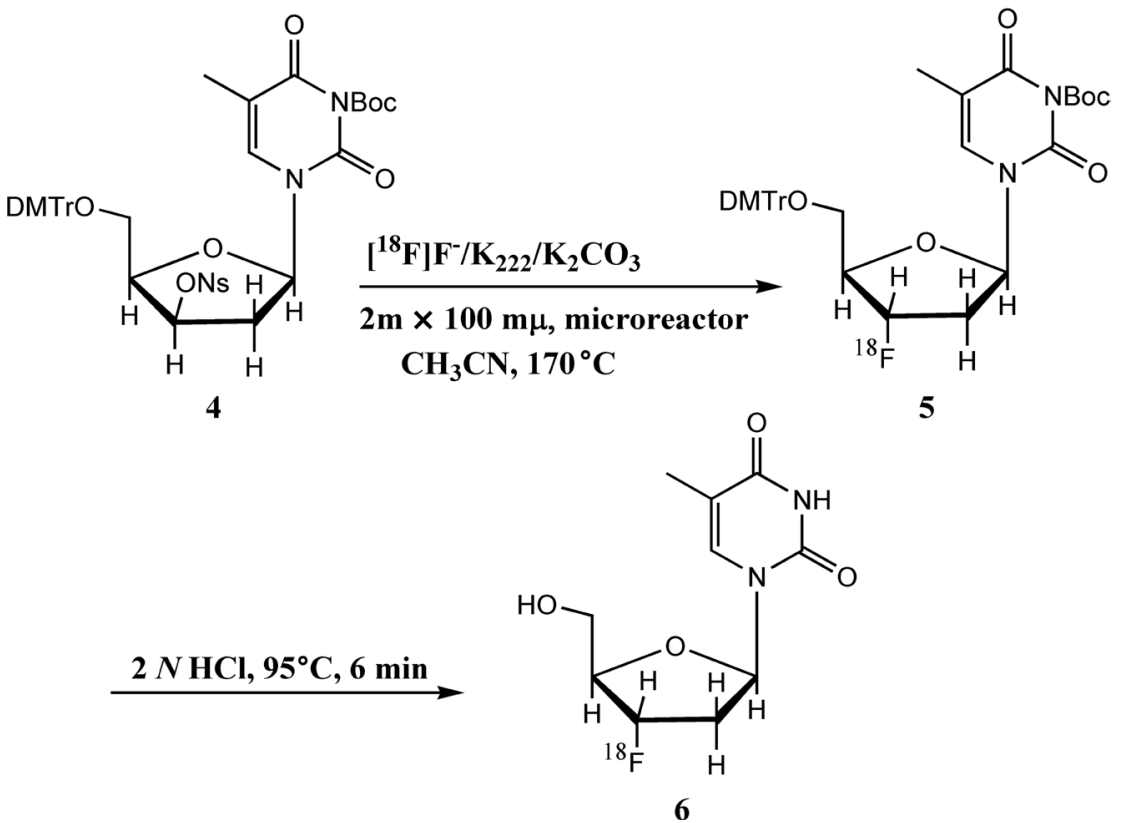

Figure 2. The synthesis of $\left[{ }^{18} \mathrm{~F}\right] \mathrm{FLT}$ according to the reported procedure [16].

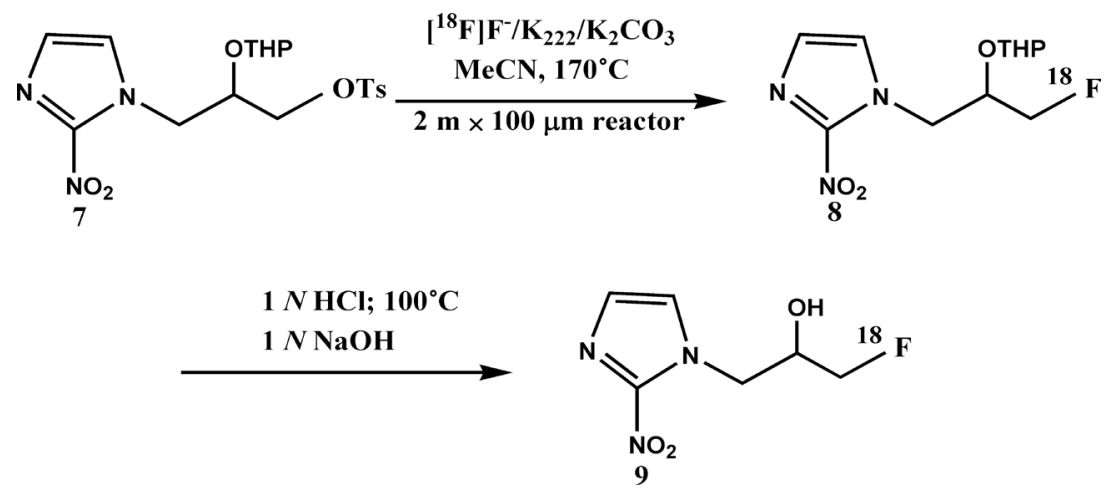

Figure 3. Synthesis of $\left[{ }^{18} \mathrm{~F}\right] \mathrm{FMISO}$. 


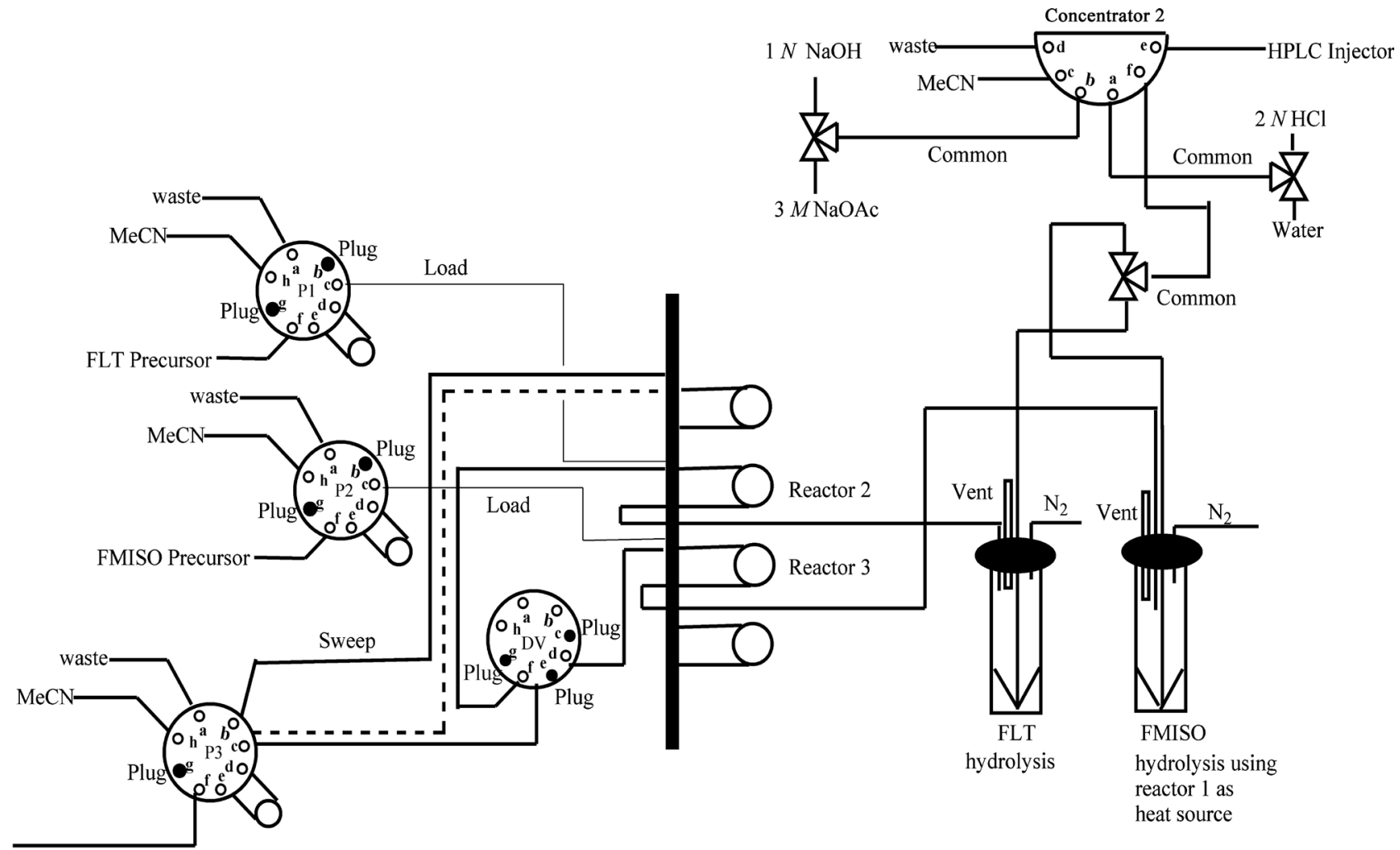

Dry $\mathrm{F}^{-}$from concentrator 1

Figure 4. Modification of NanoTek System for sequential synthesis of $\left[{ }^{18} \mathrm{~F}\right] \mathrm{FLT}$ and $\left[{ }^{18} \mathrm{~F}\right] \mathrm{FMISO}$.

shown in Figure 4, was used to dry the isotope. Pump P3 delivered the anhydrous isotope dissolved in acetonitrile to reactors 2 and 3. Pumps P1 and P2 transferred the precursors of FLT 4 and FMISO 7 respectively. Concentrator 2 delivered the reagents to the hydrolysis vials. Additionally, the port E of concentrator 2 was used to transfer the reaction mixture to an HPLC injector. The dotted line indicates the standard fluoride line connected to port C of pump P3.

This line was replaced with the line to DV common to make a switch from the standard mode to sequential mode. Also, P1 port $\mathrm{C}$ line from reactor 1 was moved to reactor 2. All of the reactors in the reactor module were shifted one position down in order to free up reactor 1 for hydrolysis block. F-18 labelling was performed in a $100 \mu \mathrm{m} \times 2 \mathrm{~m}$ reactor using Advion NanoTek Microfluidic Synthesis System controlled by NanoTek LF 1.4 Software. Solvent selector and column selector valves were used to direct the HPLC purification of the desired products. No-carrier-added $\left[{ }^{18} \mathrm{~F}\right] \mathrm{F}^{-}$, produced from recycled $\left[{ }^{18} \mathrm{O}\right]$ water, was obtained from PET Net (Knoxville, TN). Thin-layer chromatography visualization was performed with radiation detectors using a BioScan AR-2500 radio-TLC reader and Win Scan 1.3 software. All radio-TLC plates were developed using methanol as the eluent. Crude products were purified by semi-preparative HPLC on PerkinElmer 200 system using a Phenomenex Luna $\mathrm{C}_{18}$ reverse phase column $(250 \times 10 \mathrm{~mm}, 10 \mu)$ and an Econosphere reverse phase column $(250 \times$ $10 \mathrm{~mm}, 10 \mu$ ) respectively. Analytical radio-HPLC analyses were performed on 
an Agilent 1200 series instrument by a $254 \mathrm{~nm}$ UV detector, Bioscan Photomultplier Raddiation Detector and a Phenomenex Luna $\mathrm{C}_{18}$ column, $5 \mu, 4.6 \times$ $250 \mathrm{~mm}$, using $6 \%$ ethanol/94\% water as the eluent at a flow rate of $1 \mathrm{~mL} / \mathrm{min}$.

Cyclotron produced $\left[{ }^{18} \mathrm{~F}\right]$ fluoride $(678 \mathrm{mCi})$ was trapped onto ORTG ion exchange cartridge to remove $\left[{ }^{18} \mathrm{O}\right]$ water and the isotope was eluted with a mixture of kryptofix- $\mathrm{K}_{2} \mathrm{CO}_{3}$ in $\mathrm{CH}_{3} \mathrm{CN}: \mathrm{H}_{2} \mathrm{O}$. The isotope was azeotropically dried with acetonitrile $(3 \times 100 \mu \mathrm{L})$ and the complex $\left[{ }^{18} \mathrm{~F}\right] \mathrm{F}$-/ kryptofix- $\mathrm{K}_{2} \mathrm{CO}_{3}$ was dissolved in $\mathrm{CH}_{3} \mathrm{CN}(2 \mathrm{~mL}) .1 \mathrm{~mL}$ each of this solution was used for the synthesis of the two tracers. Optimum conditions for the synthesis of $\left[{ }^{18} \mathrm{~F}\right] \mathrm{FLT}$ and $\left[{ }^{18} \mathrm{~F}\right] \mathrm{FMISO}$ and purification are presented in Table 1 .

The results of the sequential synthesis of the two tracers are presented in $\mathrm{Ta}$ ble 2 .

\section{Conclusions}

Using Advion NanoTek Microfluidic Synthesis platform, we were able to successfully make both $\left[{ }^{18} \mathrm{~F}\right] \mathrm{FLT}$ and $\left[{ }^{18} \mathrm{~F}\right] \mathrm{FMISO}$ sequentially. The decay corrected radio chemical yields of $\left[{ }^{18} \mathrm{~F}\right] \mathrm{FLT}$ and $\left[{ }^{18} \mathrm{~F}\right] \mathrm{FMISO}$ were found to be $28.5 \%$ and $38.6 \%$ respectively. The specific activity was determined to be $>2 \mathrm{Ci} / \mu \mathrm{mol}$. The radiochemical purity of $\left[{ }^{18} \mathrm{~F}\right] \mathrm{FLT}$ was $>99 \%$ and of $\left[{ }^{18} \mathrm{~F}\right] \mathrm{FMISO}$ was $>97 \%$.

Table 1. Synthesis conditions and HPLC purification. The time of peak collection was optimized using radiation detector.

\begin{tabular}{ccc}
\hline Item & {$\left[{ }^{18} \mathrm{~F}\right] \mathrm{FLT}$} & {$\left[{ }^{18} \mathrm{~F}\right] \mathrm{FMISO}$} \\
\hline Reactor Temperature ${ }^{-}$ & $170^{\circ} \mathrm{C}$ & $170^{\circ} \mathrm{C}$ \\
Reactor Flow Rate & $150 \mu \mathrm{l} / \mathrm{min}$ & $150 \mu \mathrm{L} / \mathrm{min}$ \\
Precursor Concentration in $\mathrm{CH}_{3} \mathrm{CN}$ & $20 \mathrm{mg} / \mathrm{mL}$ & $5 \mathrm{mg} / \mathrm{mL}$ \\
Acid Hydrolysis & $2 N \mathrm{HCl} / 2 \mathrm{~mL}$ & $1 N \mathrm{HCl} / 0.5 \mathrm{~mL}$ \\
Neutralization & $95^{\circ} \mathrm{C}(6 \mathrm{~min})$ & $100^{\circ} \mathrm{C}(5 \mathrm{~min})$ \\
Semi-Preparative HPLC & $3 N \mathrm{NaOAc} / 2 \mathrm{~mL}$ & $1 N \mathrm{NAOH} / 1 \mathrm{~mL}$ \\
Flow Rate & $8 \% \mathrm{EtOH}$ in PBS & $5 \% \mathrm{EtOH}$ in $\mathrm{H}_{2} \mathrm{O}$ \\
Time of Peak Collection & $5 \mathrm{~mL} / \mathrm{min}$ & $5 \mathrm{~mL} / \mathrm{min}$ \\
& $\sim 12 \mathrm{~min}$ & $\sim 9 \mathrm{~min}$ \\
\hline
\end{tabular}

Table 2. SOS = start of the synthesis; EOS = end of the synthesis; RCY = radiochemical yield; RCP = radiochemical purity: 1 . The RCY \% was calculated by dividing the activity of purified product by half of staring $\mathrm{F}^{-} \times 100$.

\begin{tabular}{ccccccc}
\hline $\begin{array}{c}\text { Activity } \\
\mathrm{mCi}\end{array}$ & Tracer & Time & $\begin{array}{c}\text { Activity } \\
\text { SOS }\end{array}$ & $\begin{array}{c}\text { RCY } \% \\
\text { EOS }^{1}\end{array}$ & $\begin{array}{c}\text { RCY } \% \\
\text { SOS }\end{array}$ & RCP \% \\
\hline 678 & Starting F & 10.25 & 678 & & & \\
59.4 & {$\left[{ }^{-} \mathrm{F}\right] \mathrm{FLT}$} & 11.42 & 96.7 & 17.5 & 28.5 & $>99$ \\
57.4 & {$\left[{ }^{18} \mathrm{~F}\right] \mathrm{FMISO}$} & 12.35 & 130.8 & 16.9 & 38.6 & $>97$ \\
\hline
\end{tabular}




\section{Acknowledgements}

We wish to thank Molecular Imaging and Translational Research Program for the financial support.

\section{Conflicts of Interest}

The authors declare no conflicts of interest regarding the publication of this paper.

\section{References}

[1] Adrian, H. (2007) Angewandte Chemie International Edition in English, 46, 1772.

[2] Lu, S.Y. and Pike, V.W. (2006) Micro-Reactors for PET Tracer Labeling. In: Schubiger, P.A., Lehman, L. and Friebe, M., Eds., PET Chemistry: The Driving Force in Molecular Imaging, Springer Verlag, Berlin, 271-289.

https://doi.org/10.1007/978-3-540-49527-7_10

[3] Fortt, R. and Gee, A. (2013) Microfluidics: A Golden Opportunity for Positron Emission Tomography? Future Medicinal Chemistry, 5, 241. https://doi.org/10.4155/fmc.13.8

[4] Miller, P.W. (2009) Radiolabelling with Short-Lived PET (Positron Emission Tomography) Isotopes Using Microfluidic Reactors. Journal of Chemical Technology \& Biotechnology, 84, 309-315. https://doi.org/10.1002/jctb.2061

[5] Miller, P.W., de Mello, A.J. and Gee, A.D. (2010) Application of Microfluidics to the Ultra-Rapid Preparation of Fluorine-18 Labelled Compounds. Current Radiopharmaceuticals, 3, 254-262. https://doi.org/10.2174/1874471011003030254

[6] Lucignani, G. (2006) Pivotal Role of Nanotechnologies and Biotechnologies for Molecular Imaging and Therapy. European Journal of Nuclear Medicine and Molecular Imaging, 33, 849-851. https://doi.org/10.1007/s00259-006-0149-8

[7] Shen, C.K. (2011) Microfludic-Assisted Radiochemistry and PET Probe Synthesis. MI Gateway, 5, 1

[8] Pascali, G., Matesic, L., Collier, T.L., Wyatt, N. and Fraser, B.H. (2014) Optimization of Nucleophilic ${ }^{18} \mathrm{~F}$ Radiofluorinations Using a Microfluidic Reaction Approach. Nature Protocols, 9, 2017-2029. https://doi.org/10.1038/nprot.2014.137

[9] Briard, E., Zoghbi, S.S., Simeon, F.G., Imaizumi, M., Gourley, J.P., Shetty, H.U., Lu, S., Fuhita, M., Innis, R.B. and Pike, V.W. (2009) Single-Step High-Yield Radiosynthesis and Evaluation of a Sensitive ${ }^{18} \mathrm{~F}$-Labeled Ligand for Imaging Brain Peripheral Benzodiazepine Receptors with PET. Journal of Medicinal Chemistry, 52, 688-699. https://doi.org/10.1021/jm8011855

[10] Wester, H.J., Schoultz, B.W., Hultsch, C. and Henriksen, G. (2009) Fast and Repetitive In-Capillary Production of $\left[{ }^{18} \mathrm{~F}\right] \mathrm{FDG}$. European Journal of Nuclear Medicine and Molecular Imaging, 36, 653. https://doi.org/10.1007/s00259-008-0985-9

[11] Pascali, G., Mazzone, G., Saccomanni, G., Manera, C. and Salavadori, P.A. (2010) Microfluidic Approach for Fast Labeling Optimization and Dose-on-Demand Implementation. Nuclear Medicine and Biology, 37, 547-555.

[12] Liu, K., Lepin, E.J., Wang, M.W., Guo, F., Lin, W.Y., Chen, Y.C., Sirk, S.J., Olma, S., Phelps, M.E. and Zhao, X.Z. (2010) Micro Chip Based F-18 Labeling of Biomolecules for Immuno Positron Emission Tomography. Molecular Imaging, 10, 168.

[13] Liang, S.H., Yokell, D.L., Rice, P.A., Jackson, R.N., Callahan, R., Jackson, K.A., Alagille, D., Tamagnan, G., Collier, T.L. and Vasdev, N. (2014) Microfluidic Conti- 
nuous-Flow Radiosynthesis of $\left[{ }^{18} \mathrm{~F}\right]$ FPEB Suitable for Human PET Imaging. Medicinal Chemistry Communication, 5, 432-435. https://doi.org/10.1039/C3MD00335C

[14] Collier, T., Zheng, M., Bois, F., Hammond, K., Akula, M., Kabalka, G. and Huang, Y. (2015) Synthesis of $\left[{ }^{18} \mathrm{~F}\right] \mathrm{FMISO}$ in a Flow Through Microfluidic Reactor: Development and Clinical Application. Nuclear Medicine and Biology, 42, 578. https://doi.org/10.1016/j.nucmedbio.2015.01.010

[15] Liang, S.H., Yokell, D.L., Normandin, M.D., Rice, P.A., Jackson, R.N., Shopu, T.M., Brady, T.J., Fakhri, G., Collier, T.L. and Vasdev, N. (2014) First Human Use of Radiopharmaceutical Prepared by Continuous-Flow Microfluidic Radiofluorination: Proof of Concept with the Tau imaging. Molecular Imaging, 13, 1.

[16] Martin, S.T., Eisenbarth, J.A., Wagner-Uterman, U., Mier, W., Henz, M., Pritzkov, H., et al. (2002) A new precursor for the radiosynthesis of $\left[{ }^{18} \mathrm{~F}\right] \mathrm{FLT}$. Nuclear Medicine and Biology, 29, 263.

[17] Yun, M., Oh, S.J., Ha, H.J., Ryu, J.S. and Moon, D.H. (2003) High Radiochemical Synthesis of 3 '-deoxy-3'-[ $\left.{ }^{18} \mathrm{~F}\right]$ fluorothymidine using (5'-O-dimethoxytrityl-2'-deoxy3'-O-nosyl-beta-D-threo pentafuranosyl)thymidine and Its 3-N-Boc Protected Analogue as a Labeling Precursor. Nuclear Medicine and Biology, 30, 151.

[18] Bollineni, V.R., Kramer, G.M., Jansma, E.P., Liu, Y. and Oyen, W.J. (2016) A Systematic Review on $\left[{ }^{18} \mathrm{~F}\right.$ ] FLT-PET Uptake as a Measure of Treatment Response in Cancer Patients. European Journal of Cancer, 55, 81-97.

https://doi.org/10.1016/j.ejca.2015.11.018 